\title{
Evaluation of biorelevant media to investigate the dissolution properties on flurbiprofen and to assess cytotoxicity effects on Caco-2 cell line
}

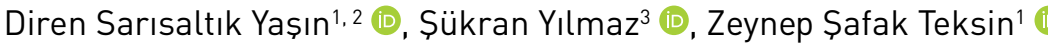 \\ 'Department of Pharmaceutical Technology, Faculty of Pharmacy, Gazi University, 06330 Ankara, Turkey \\ 2Department of Pharmaceutical Technology, Faculty of Pharmacy, Dicle University, 21280 Diyarbakır, Turkey \\ ${ }^{3}$ Foot and Mouth Disease Institute, 06044 Ankara, Turkey
}

Cite this article as: Sarısaltık Yașın D, Yılmaz Ș, Teksin ZȘ (2018). Evaluation of biorelevant media to investigate the dissolution properties on flurbiprofen and to assess cytotoxicity effects on Caco-2 cell line. Istanbul J Pharm 48 (3): 82-88.

\begin{abstract}
Biorelevant media are used to simulate the physiological conditions in terms of components, $\mathrm{pH}$, osmolality and buffer capacity of the human stomach and intestine in both fasted and fed states In this study, we aim to apply the biorelevant media to Caco-2 cell lines to investigate the cytotoxicity effects via the cell viability ratio and to compare the solubilizing effects of various dissolution media on a poorly soluble model drug. Flurbiprofen (Biopharmaceutics Classification System, BCS Class 2) was selected as a model drug.

In dissolution studies the $\mathrm{pH}$ effects were predominant at higher $\mathrm{pH}$ values, while bile salt effects were dominant at lower $\mathrm{pH}$ values. The preparation method, bile salts and the phospholipids did not show any additional effect on Caco-2 cell viability. In the cytotoxicity test, fed state media caused an additional 10-15\% decrease in cell viability, compared to the fasted state. Similar results were obtained when using the blank of these media which did not include the bile salt or phospholipid. From this, it is evident that this decrease resulted from the $\mathrm{pH}$ values, not the components. In conclusion, the cytotoxicity assessment showed that all the biorelevant media were compatible with $70-90 \%$ of cell viability for at least $24 \mathrm{~h}$, and this ratio might be increased by modifying the $\mathrm{pH}$.
\end{abstract}

Keywords: Biorelevant media, flurbiprofen, cytotoxicity

\section{INTRODUCTION}

Many studies have been conducted to develop a dissolution media which better reflects the contents of the human gastrointestinal system. In those studies, researchers added some enzymes, surfactants, bile salts, phospholipids, lipolysis products etc. to the media (Dressman et al. 1998; Galia et al. 1998; Tang et al. 2001; Wiedman et al. 2002; Jantraid et al. 2008). Additionally, pH, surface tension, and the osmolality of these media were taken into consideration. Regarding the effect of food on the absorption of BCS Class 2 drugs, the dissolution media for the fed state were also developed separately (Dressman et al. 1998; Galia et al. 1998; Jantraid et al. 2008).

Health authorities have not yet approved any biorelevant media other than compendial media. However, Dressman developed two basic media for reflecting intestine in the fasted and fed states (Dressman et al. 1998). These media are known as Fasted State Simulated Intestinal Fluid (FaSSIF) and Fed State Simulated Intestinal Fluid (FeSSIF). These media have attracted the attention of a many scientists and much research has been conducted in their use (Galia et al. 1998; Nicolaides et al. 1999; Kostewicz et al. 2002; Fagerberg et al. 2010). Moreover, several other media were developed based on these media (Marquez 2004; Jantraid et al. 2008; Fatouros et al. 2009; Kleberg et al. 2010; Klein 2010; Fuchs et al. 2015; Zhou et al. 2017). When the dissolution tests that were performed using these media provided a better correlation in vivo (Mathias et al. 2015; Xu et al. 2017), researchers started to use them in permeability studies (Patel et al. 2006; Birch et al. 2018). However, certain components in these media such as bile salts and phospholipids raised suspicions regarding the possible toxic effects on cell lines (Ingels 
and Augustijns 2003; Birch et al. 2018). Apart from the components of these media, the preparation process is also important. Due to the physicochemical properties of bile salts and lecithin and the use of organic solvents in the process, the preparation of these media is not simple. To standardize the media preparation, an instant powder mix of these components was obtained (SIF Powder") by Biorelevant.com (Boni et al. 2009).

Flurbiprofen is a rapidly absorbed, non-steroidal anti-inflammatory drug, with $96 \%$ oral bioavailability following oral administration. Absorption is increased with food (Pargal et al. 1996) and it eliminates $75-80 \%$ as metabolites and $20-25 \%$ as the unchanged drug in the urine. Flurbiprofen is a weak acid with a $\mathrm{pK}_{\mathrm{a}}$ of 4.22 . It is a BCS Class 2 drug and practically insoluble in water. It has a solubility of 0.0080 $\mathrm{mg} / \mathrm{mL}$ at $\mathrm{pH} 1.2$ and its solubility increases with $\mathrm{pH}$ (Li and Zhao 2003). Yazdanian et al. calculated the permeability $\left(P_{a p p}\right)$ of flurbiprofen as higher than verapamil used as the reference drug with a $P_{\text {app }}$ of $20.1 \times 10^{6} \pm 2.7 \times 10^{6} \mathrm{~cm} / \mathrm{s}(Y a z-$ danian et al. 2004).

In this study, we aim to evaluate the possible cytotoxic effects of a high permeable model drug when prepared conventionally and when prepared from the instant powder. For this reason, we selected a BCS Class 2 drug - flurbiprofen. Moreover, we performed solubility and dissolution tests with the commercial product containing the model drug to compare the media against themselves. In addition to the biorelevant media, pharmacopeial media and blank media not including the bile salts and phospholipids were also used to assess the $\mathrm{pH}$ effects.

\section{MATERIALS AND METHODS}

Sodium taurocholate 97\% pure (high quality: HQ), egg-phosphatidylcholine, MTT and trypan blue were purchased from Sigma-Aldrich (USA). All the chemicals and reagents were purchased from Merck (Germany). SIF Powder (Biorelevant. com, United Kingdom) is a patented formulation of sodium taurocholate and lecithin with the molar ratio of 4:1 which corresponds with Dressman's formulation (Dressman et al. 1998).
The biorelevant media prepared using instant powder are defined as SIF-FaSSIF and SIF-FeSSIF in this study.

Dulbecco's Modified Eagle's Medium (DMEM), EDTA, Fetal bovine serum (FBS) and RPMI 1640 were purchased from Biochrom, Germany and Caco-2 cells were obtained from Cell Culture Collection, Turkey. Flurbiprofen (Sun Pharmaceuticals, India) was supplied from Drogsan Pharmaceuticals (Turkey). Ansaid" (Pfizer, Turkey) 100 mg film-coated tablets were purchased from a local drug market.

\section{Preparation of dissolution media}

The classical dissolution media of $\mathrm{pH} 1.2, \mathrm{pH} 4.5$, and $\mathrm{pH} 6.8$ were prepared according to USP. FaSSIF and FeSSIF were prepared as previously reported (Marquez 2004). SIF-FaSSIF and SIF-FeSSIF, Blank FaSSIF, Blank FeSSIF were prepared in accordance with the protocols of Biorelevant.com. The compositions of the biorelevant media and blank media are shown in Table 1.

\section{Solubility}

Solubility measurements of the samples were performed using the shake-flask method and all the solubility experiments were conducted in triplicate. According to the method, the excess of the drug powder was added to $50 \mathrm{~mL}$ of different dissolution media and stirred at $37.0^{\circ} \mathrm{C} \pm 0.1^{\circ} \mathrm{C}$ in a shaking incubator water bath. The equilibrium time was set to $24 \mathrm{~h}$. The final solution was then filtered through a $0.45 \mu \mathrm{m}$ (Millipore Millex-HV, USA) membrane filter and analyzed using a UV spectrophotometer (Shimadzu, UV-170, Japan). To evaluate the solubility results of the drug, dose number $\left(D_{0}\right)$, which is defined as the ratio of drug concentration in the administered volume to the saturation solubility of the drug (Oh et al. 1993) was used. It was calculated using Equation 1.

$D_{0}=\frac{M_{0} / V_{0}}{C_{S}}$

where $M_{0}$ is the dose of drug administered, $V_{0}$ is the administered volume, and $C_{s}$ is the saturation solubility. Fluid volume used with the drug was set as $250 \mathrm{~mL}$ - the volume of a glass

Table 1. Compositions of the FaSSIF and FeSSIF (Dressman et al. 1998; Biorelevant.com)

\begin{tabular}{|c|c|c|c|c|c|c|}
\hline Compositions & FaSSIF* & FeSSIF* & SIF-FaSSIF & SIF-FeSSIF & Blank FaSSIF & Blank FeSSIF \\
\hline Sodium taurocholate & $3 \mathrm{mM}$ & $15 \mathrm{mM}$ & $3 \mathrm{mM}$ & $15 \mathrm{mM}$ & - & - \\
\hline Lecithin & $0.75 \mathrm{mM}$ & $3.75 \mathrm{mM}$ & $0.75 \mathrm{mM}$ & $3.75 \mathrm{mM}$ & - & - \\
\hline $\mathrm{NaH}_{2} \mathrm{PO}_{4} \cdot \mathrm{H}_{2} \mathrm{O}$ & $1.977 \mathrm{~g}$ & - & $1.977 \mathrm{~g}$ & - & $1.977 \mathrm{~g}$ & - \\
\hline Glacial acetic acid & - & $8.65 \mathrm{~g}$ & - & $8.65 \mathrm{~g}$ & - & $8.65 \mathrm{~g}$ \\
\hline $\mathrm{NaCl}$ & $3.093 \mathrm{~g}$ & $11.874 \mathrm{~g}$ & $3.093 \mathrm{~g}$ & $11.874 \mathrm{~g}$ & $3.093 \mathrm{~g}$ & $11.874 \mathrm{~g}$ \\
\hline $\mathrm{NaOH}$ (pellets) & $0.174 \mathrm{~g}$ & $4.04 \mathrm{~g}$ & $0.174 \mathrm{~g}$ & $4.04 \mathrm{~g}$ & $0.174 \mathrm{~g}$ & $4.04 \mathrm{~g}$ \\
\hline Deionized water (qs) & $500 \mathrm{~mL}$ & $1000 \mathrm{~mL}$ & $500 \mathrm{~mL}$ & $1000 \mathrm{~mL}$ & $500 \mathrm{~mL}$ & $1000 \mathrm{~mL}$ \\
\hline $\mathrm{pH}$ & 6.5 & 5.0 & 6.5 & 5.0 & 6.5 & 5.0 \\
\hline \multicolumn{7}{|c|}{$\begin{array}{l}\text { *Lecithin was dissolved in dichloromethane, after emulcification dichloroethane was evaporated. } \\
\text { FaSSIF: Fasted State Simulated Intestinal Fluid, FeSSIF: Fed State Simulated Intestinal Fluid, SIF-FaSSIF: Fasted State Simulated Intestinal } \\
\text { Fluid prepared using instant powder, SIF-FeSSIF: Fed State Simulated Intestinal Fluid prepared using instant powder, Blank FaSSIF: Fasted } \\
\text { State Simulated Intestinal Fluid media not including the bile salts and phospholipids, Blank FeSSIF: Fed State Simulated Intestinal Fluid media } \\
\text { not including the bile salts and phospholipids }\end{array}$} \\
\hline
\end{tabular}


of water. While a $D_{0}$ which is equal to or lower than 1 means a high-solubility, a $\mathrm{D}_{0}$ higher than 1 indicates a low-solubility.

\section{In vitro dissolution studies}

USP apparatus 2 (PharmaTest, Germany) was used for all dissolution tests. The dissolution studies were carried out at $37 \pm 0.5^{\circ} \mathrm{C}$ in $900 \mathrm{~mL}$ of dissolution media and with a rotational speed of $50 \mathrm{rpm}$. At each predetermined sample time intervals $(5,10,15,20,30,45$ and 60 minutes), $5 \mathrm{~mL}$ of the sample was taken, and $5 \mathrm{~mL}$ of blank medium was replaced. All samples were filtered using $0.45 \mu \mathrm{m}$ (Millipore Millex-HV, USA) membrane filter and after diluting, they were analyzed by the validated UV spectrophotometric method (Shimadzu, UV-170, Japan). All experiments were performed in triplicate. The dissolution test results were evaluated using the similarity factor $\left(f_{2}\right)$ to compare the mediums.

$f_{2}=50 . \log \left\{\left[1+\left(\frac{1}{n}\right) \sum_{t=1} n\left(R_{t}-T_{t}\right)^{2}\right]^{-0.5} .100\right\}$

Where $n$ is the number of time points, $R_{t}$ is the dissolved amount of the reference at time $t$, and $T_{t}$ is the dissolved amount of the test at time $t$.

\section{Spectrofotometric analysis}

A Shimadzu UV-170 Spectrophotometer (Japan) was used for UV analysis. All assay and dissolution studies were analyzed using a UV-spectrometer. The maximum absorbance values of the drugs in various media were different. The wavelengths $\left(\lambda_{\text {max }}\right)$ that are being used were $246 \mathrm{~nm}(\mathrm{pH} 4.5, \mathrm{pH}$ 6.8, Blank FaSSIF, FaSSIF and Blank FeSSIF), $248 \mathrm{~nm}$ (SIF-FeSSIF) and 250 $\mathrm{nm}$ (FeSSIF and SIF-FeSSIF).

\section{Cytotoxicity assessments}

Caco- 2 cells were grown at $37^{\circ} \mathrm{C}$ in an atmosphere of $5 \% \mathrm{CO}_{2}$ in Dulbecco's Modified Eagle Medium (DMEM) supplemented

Table 2. Solubility and dose number values of flurbiprofen in different dissolution media.

\begin{tabular}{lccc}
$\begin{array}{l}\text { Dissolution } \\
\text { media }\end{array}$ & $\begin{array}{c}\text { Solubility } \pm \text { SD } \\
(\mathrm{mg} / \mathrm{mL})\end{array}$ & $\mathrm{D}_{0} \pm \mathrm{SD}$ & $\begin{array}{c}\text { Dissolved \% } \\
\text { in } 30 \mathrm{~min} \\
\text { Mean } \pm \text { SD }\end{array}$ \\
\hline $\mathrm{pH} 4.5$ & $0.0555 \pm 0.0003$ & $7.21 \pm 0.04$ & $39.6 \pm 0.4$ \\
$\mathrm{pH} 6.8$ & $2.53 \pm 0.05$ & $0.323 \pm 0.006$ & $90.9 \pm 0.9$ \\
BlankFaSSIF & $1.78 \pm 0.03$ & $0.224 \pm 0.003$ & $93.2 \pm 1.7$ \\
FaSSIF & $1.25 \pm 0.02$ & $0.158 \pm 0.003$ & $95.7 \pm 3.0$ \\
SIF-FaSSIF & $1.70 \pm 0.01$ & $0.237 \pm 0.001$ & $98.6 \pm 0.9$ \\
BlankFeSSIF & $0.0756 \pm 0.0014$ & $5.29 \pm 0.09$ & $58.3 \pm 1.0$ \\
FeSSIF & $0.529 \pm 0.007$ & $0.756 \pm 0.011$ & $76.1 \pm 2.4$ \\
SIF-FeSSIF & $4.20 \pm 0.02$ & $0.0946 \pm 0.0005$ & $104.5 \pm 0.1$
\end{tabular}

$\mathrm{D}_{0}$ : Dose number, SD: Standard deviation, FaSSIF: Fasted State Simulated Intestinal Fluid, FeSSIF: Fed State Simulated Intestinal Fluid, SIF-FaSSIF: Fasted State Simulated Intestinal Fluid prepared using instant powder, SIF-FeSSIF: Fed State Simulated Intestinal Fluid prepared using instant powder, Blank FaSSIF: Fasted State Simulated Intestinal Fluid media not including the bile salts and phospholipids, Blank FeSSIF: Fed State Simulated Intestinal Fluid media not including the bile salts and phospholipids with 10\% fetal bovine serum. A confluent cell line was washed with trypsin/EDTA solution (0.05\%/0.02\%) and kept in an incubator for 5-10 minutes and then centrifuged. The cell line was homogenized by DMEM with $10 \%$ of serum and $1 \%$ of antibiotic. Three passages were performed. For the cell count $0.1 \mathrm{~mL}$ of trypan blue was added to $0.9 \mathrm{~mL}$ of cell suspension and the cell count was conducted by a hemacytometer. The cell viability was then checked with an optical microscope. The cells were homogenized in DMEM containing 10\% FBS and 1\% antibiotic and then a $4 \times 10^{4} \mathrm{cell} / \mathrm{mL}$ cell suspension was prepared and transferred to $96-$ well cell plates $(100 \mu \mathrm{L} /$ well $)$ and incubated in $5 \% \mathrm{CO}_{2}$ for 24 hours.

\section{MTT viability test}

The MTT [3-(4,5-Dimethylthiazol-2-yl)-2,5-Diphenyltetrazolium Bromide] test is a colorimetric assay test that can be used to determine cell viability (mitochondrial activity) measuring the extent of formazan formation after the lysis of the living material and the solubilization of formazan crystals (Berridge et al 2005).

The MTT [3-(4,5-Dimethylthiazol-2-yl)-2,5-Diphenyltetrazolium Bromide] test was performed to evaluate the cytotoxicity of sodium taurocholate, lecithin and flurbiprofen in biorelevant media with incubation times of 1 and 24 hours and concentrations of $100 \mu \mathrm{M}$ and $500 \mu \mathrm{M}$. These concentrations were selected with reference to previous transport studies (Laitinen et al. 2007). The cell viability values were calculated as a percentage in control groups according to the following equation:

Cell viability $(\%)=\frac{A_{\text {test }}}{A_{\text {control }}} \times 100$

where $A_{\text {test }}$ is the absorbance of test and $A_{\text {control }}$ is the absorbance of DMEM.

\section{RESULTS AND DISCUSSSION}

\section{Solubility}

The solubility studies were assessed following two methods: 1) the effect of $\mathrm{pH}$ and 2) the effect of concentrations of sodium taurocholate and lecithin. In addition, the preparation method of the biorelevant media was also considered. The solubility test results of flurbiprofen and estimated dose figures are summarized in Table 2. Flurbiprofen is a weak acid, thereby it is soluble when the $\mathrm{pH}$ value is greater than its $\mathrm{pK}_{\mathrm{a}}$ value of 4.22. For this reason, flurbiprofen did not practically dissolve at $\mathrm{pH} 1.2$ and the solubility increased with $\mathrm{pH}$. When the solubilization effects of sodium taurocholate and lecithin were not considered, flurbiprofen showed the maximum solubility at $\mathrm{pH} 6.8$, the highest $\mathrm{pH}$. The solubility at $\mathrm{pH} 6.8$ was four times higher than at $\mathrm{pH}$ 4.5. The solubility values of flurbiprofen at different $\mathrm{pH}$ levels (Table 2) were in a strong correlation with the literature data (Li and Zhao 2003). To evaluate the effect of sodium taurocholate and lecithin in the fasted state (Table 3), Blank FaSSIF was compared with FaSSIF and SIF-FaSSIF. The solubility values of flurbiprofen in Blank FaSSIF, FaSSIF, and SIF-FaSSIF, while similar, were lower than 
the solubility at pH 6.8 media which has a higher $\mathrm{pH}$ value than biorelevant media. Interestingly, neither FaSSIF nor SIFFaSSIF provided a more significant increase than Blank-FaSSIF. To investigate the food effect on flurbiprofen solubility, we compared the Blank FeSSIF, FeSSIF and SIF-FeSSIF. The solubility of flurbiprofen was increased seven-fold in FeSSIF compared with Blank FaSSIF. However, in SIF-FeSSIF flurbiprofen was eight times more soluble than FeSSIF and 56 times more soluble than Blank-FaSSIF. This dramatic variation between FeSSIF and SIF-FeSSIF is thought to result from the preparation processes. FaSSIF and FeSSIF were prepared using dichloromethane as a solvent and after the emulsification process, the organic solvent should be evaporated as reported in the literature (Dressman et al. 1998). Therefore, it is difficult to standardize the preparation method. It may be affected by the capacity of the equipment in the emulsification and evaporation processes. However, the SIF-Powder was simply dissolved in the blank mediums as described in Biorelevant media. Therefore, probable variations arising from using different analysts, equipment or time can be minimized.

Based on the $D_{0}$ values given in Table 3, flurbiprofen was found to have low solubility in pH 4.5 and blank FaSSIF $\left(D_{0}>1\right)$, while it was highly soluble $\left(D_{0}<1\right)$ in all the other media (Table 3).

\section{Table 3. Comparing the flurbiprofen dissolution curves in different media}

\begin{tabular}{|lccc} 
Test media & Reference media & $\mathbf{f}_{2}$ value* & Similarity \\
\hline Blank FaSSIF & FaSSIF & 64.2 & Similar \\
Blank FaSSIF & SIF-FaSSIF & 63.3 & Similar \\
FaSSIF & SIF-FaSSIF & 54.0 & Similar \\
Blank FeSSIF & FeSSIF & 36.2 & Not similar \\
Blank FeSSIF & SIF-FeSSIF & 16.3 & Not similar \\
FeSSIF & SIF-FeSSIF & 27.2 & Not similar
\end{tabular}

*When similarity factor, $\mathrm{f} 2 \geq 50$ dissolution curves are similar FaSSIF: Fasted State Simulated Intestinal Fluid, FeSSIF: Fed State Simulated Intestinal Fluid, SIF-FaSSIF: Fasted State Simulated Intestinal Fluid prepared using instant powder, SIF-FeSSIF: Fed State Simulated Intestinal Fluid prepared using instant powder, Blank FaSSIF: Fasted State Simulated Intestinal Fluid media not including the bile salts and phospholipids, Blank FeSSIF: Fed State Simulated Intestinal Fluid media not including the bile salts and phospholipids

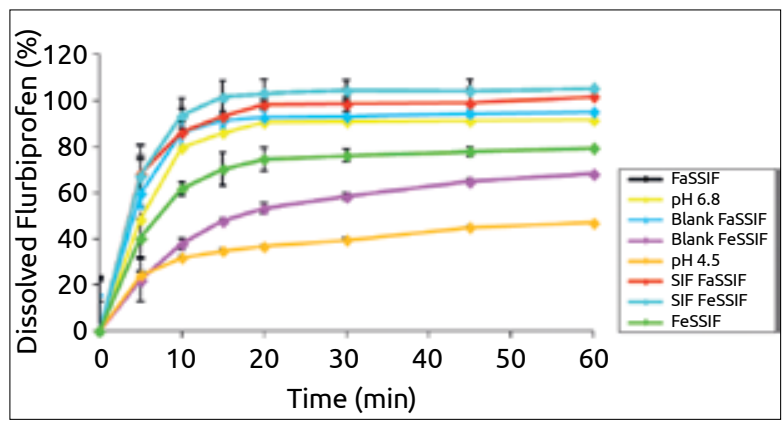

Figure 1. Dissolution profiles of flurbiprofen tablets

\section{In vitro dissolution studies}

Dissolution studies were performed to witness the media effects on BCS Class 2 drug. Ansaid (Pfizer, Turkey) 100 mg was used for the dissolution studies as a reference product for flurbiprofen. The mean dissolution profiles of flurbiprofen are shown in Figure 1. Since flurbiprofen is a weak acid with a pK of 4.22 , the ionized form of flurbiprofen increases as the $\mathrm{pH}$ of the dissolution media increases. After 1 hour, the dissolved ratio of flurbiprofen from tablets was $47 \%$ at $\mathrm{pH} 4.5$ buffer, whereas the dissolved amount was $68 \%$ in Blank FeSSIF $(\mathrm{pH}$ 5.0). Although, the dissolution of flurbiprofen increased with a pH higher than $\mathrm{pK}_{\mathrm{a}}$ of 4.22, a complete dissolution was not observed at pH 5.0. Given the use of SIF-FeSSIF containing bile salt/lecithin media with the same $\mathrm{pH}$, a great enhancement resulting in complete dissolution was observed. Nevertheless, in FeSSIF, media which includes the same amount of bile salt and lecithin, a complete dissolution was not achieved. When comparing FeSSIF and SIF-FeSSIF, the twobile salt and lecithin containing media, this significant difference is thought to result from the preparation conditions. SIF-FeSSIF is an easy-to-prepare instant powder, whereas FeSSIF involves a complicated preparation process including an organic solvent evaporation step. The similarity factors of the biorelevant media and their blanks are given in Table 3 . More than $85 \%$ of the drug was released in 30 minutes at $\mathrm{pH}$ 6.8, Blank FaSSIF, FaSSIF and SIF-FaSSIF with pH 6.5. While the $\mathrm{pH}$ effect was predominant at the higher $\mathrm{pH}$ values, bile salt effect was dominant at the lower pH levels. Therefore, thanks to the pH of FaSSIF 6.5, it may not be necessary to use the bile salts in media. However, the dissolution results of FeSSIF, Blank FeSSIF and SIF-FeSSIF were not found to be similar. SIF-FeSSIF significantly increased the release of flurbiprofen. This means that the preparation method is equally as important as the composition of the fed state biorelevant media. In line with these results, we decided to assess the preparation method of the biorelevant media when evaluating the cytotoxicity on the Caco-2 cell line.

\section{Cytotoxicity results}

The effects of sodium taurocholate and lecithin, DMSO, and flurbiprofen on the mitochondrial dehydrogenase activity were studied in the Caco-2 cell monolayers. Conventionally prepared biorelevant media (Dressman et al. 1998), and the media prepared using SIF-Powder" (the instant powder), were evaluated separately. To eliminate the $\mathrm{pH}$ effect, the media without bile salt and phospholipid (Blank media) were also investigated and DMEM without serum was used as a control. Additionally, a model drug (flurbiprofen) at two different concentrations (100 $\mu \mathrm{M}$ and $500 \mu \mathrm{M}$ ) was evaluated in these biorelevant media. Cell viability was scored according to the following classification (Dahl et al. 2006): More than 90 percent of cell viability was defined as "non-cytotoxic"; 60-90 percent of cell viability was defined as "slightly cytotoxic"; 30-59 percent of cell viability was defined as "moderately cytotoxic" and less than 30 percent of cell viability was defined as "severely cytotoxic".

Since the model drug possesses a high permeability, the initial measurement was carried out at the first hour and 
another measurement was performed, at the $24^{\text {th }}$ hour. The cell viability percents of cells in Blank FaSSIF, FaSSIF and SIF-FaSSIF were $88.4 \% \pm 7.2,93.7 \% \pm 6.7$ and $91.3 \% \pm 2.7$ after 1 hour and $73.2 \% \pm 1.5,78.5 \% \pm 1.6$ and $77.5 \% \pm 8.0$ after 24 hours, respectively (Table 4). According to the cytotoxicity classification, it was accepted as "slightly cytotoxic". When Blank FaSSIF without bile salts was compared with FaSSIF

\section{Table 4. Cell viability of the biorelevant media and their blanks}

\begin{tabular}{|lcc|}
\hline & $\begin{array}{c}\text { Cell viability }(\%) \\
\text { after } 1 \mathrm{~h}\end{array}$ & $\begin{array}{c}\text { Cell viability }(\%) \\
\text { after } 24 \mathrm{~h}\end{array}$ \\
\hline Blank FaSSIF & $88.4 \pm 7.2$ & $73.2 \pm 1.5$ \\
FaSSIF & $93.7 \pm 6.7$ & $78.5 \pm 1.6$ \\
SIF-FaSSIF & $91.3 \pm 2.7$ & $77.5 \pm 8.0$ \\
Blank FeSSIF & $86.1 \pm 2.4$ & $70.8 \pm 8.2$ \\
FeSSIF & $84.3 \pm 4.2$ & $73.2 \pm 3.0$ \\
SIF-FeSSIF & $82.4 \pm 4.8$ & $69.1 \pm 4.4$ \\
\hline
\end{tabular}

FaSSIF: Fasted State Simulated Intestinal Fluid, FeSSIF: Fed State Simulated Intestinal Fluid, SIF-FaSSIF: Fasted State Simulated Intestinal Fluid prepared using instant powder, SIF-FeSSIF: Fed State Simulated Intestinal Fluid prepared using instant powder, Blank FaSSIF: Fasted State Simulated Intestinal Fluid media not including the bile salts and phospholipids, Blank FeSSIF: Fed State Simulated Intestinal Fluid media not including the bile salts and phospholipids

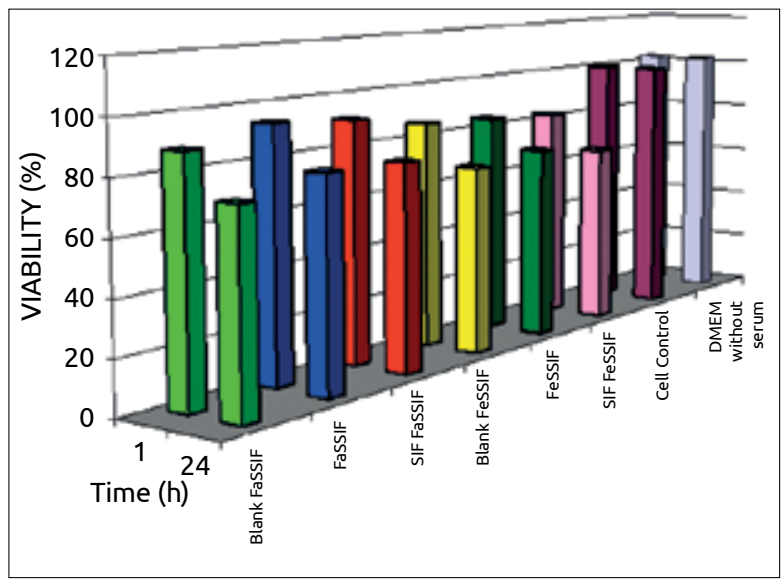

Figure 2. Viability of different dissolution media

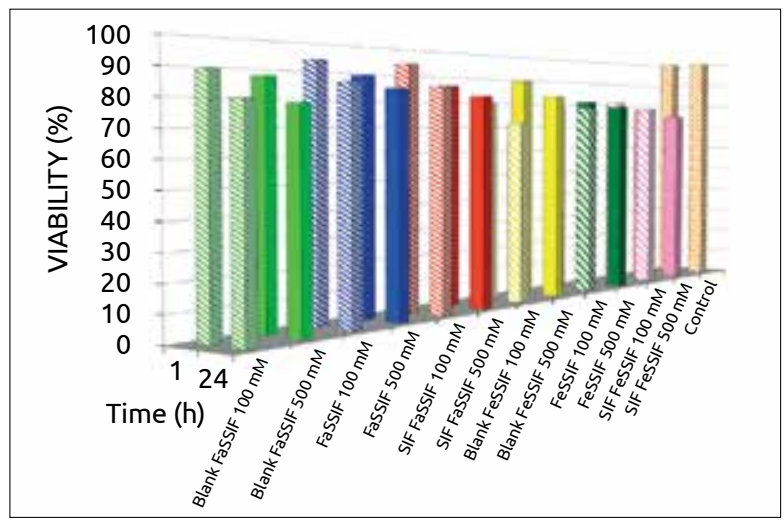

Figure 3. Viability of flurbiprofen in different dissolution media and SIF-FaSSIF which included $3 \mathrm{mM}$ sodium taurocholate and $0.75 \mathrm{mM}$ lecithin, no difference was observed. Moreover, the viability results at 24 hours were nearly $15 \%$ lower than the results at 1 hour. The viability percents of cells in Blank FeSSIF, FeSSIF and SIF-FeSSIF were $86.1 \% \pm 2.4,84.3 \% \pm 4.2$ and $82.4 \% \pm 4.8$ after 1 hour and $70.8 \% \pm 8.2,73.2 \% \pm 3.0$ and $69.1 \% \pm 4.4$ after 24 hours, respectively. According to the cytotoxicity classification, they were accepted as "slightly cytotoxic". When Blank FeSSIF without bile salts were compared with FeSSIF and SIF-FeSSIF which included $15 \mathrm{mM}$ sodium taurocholate and $3.75 \mathrm{mM}$ lecithin, no difference was observed. However, the viability results at 24 hours were lower by between 10-15\% when compare with the results at 1 hour (Figure 2). This decrease may result from the different $\mathrm{pH}$ of DMEM ( $\mathrm{pH}$ 7.4) and the biorelevant media ( $\mathrm{pH} 6.5$ for FaSSIF and pH 5.0 for FeSSIF). Antoine et al. (2015) found similar results with $83 \% \pm 24$ and $69 \% \pm 17$ of cell viability after 2 hours using FaSSIF and FeSSIF, respectively. In another study (Patel et al. 2006), while cell viability results were close to our results for FaSSIF (nearly 70\%), FeSSIF was found very cytotoxic on cells with about $10 \%$ of viability after $2 \mathrm{~h}$. For this reason, Patel et al. (2006) recommended modifications on FeSSIF when using in permeability studies. Ingels and Augustijns (2003) found 96.9\% \pm 20.1 cell viability for FaSSIF, but very low cell viability $(5.4 \% \pm 0.3)$ for FeSSIF. These results are conflicting and none of them were comparable with the blank media. Therefore, our blank-controlled study has given us more reliable results. The cell viability results are given in Table 4. The cytotoxicity results of flurbiprofen in concentrations of $100 \mu \mathrm{M}$ and $500 \mu \mathrm{M}$ were also similar to the results of the biorelevant media without the drug. The results were between $80-94 \%$ (mean value of $86.3 \pm 6.3 \%$ ) after 1 hour and $72-87 \%$ (mean value of $79.6 \pm 6.0 \%$ ) after 24 hours. These results have shown us that no additional toxic effect associated with the drug was obtained considering the viability results of cells (Figure 3 ).

As flurbiprofen is a weak acid, its solubility was affected by both $\mathrm{pH}$ and the bile salt content of the dissolution media. The effect of the bile salt content was found more significant in the media at $\mathrm{pH}$ values lower than the pKa of flurbiprofen, while the $\mathrm{pH}$ effect was more distinctive at higher $\mathrm{pH}$ values. Likewise, biorelevant media which was prepared using SIFPowder", gave more notable results in solubility and dissolution studies of flurbiprofen. Moreover, the decision to apply a biowaiver can be considered for flurbiprofen which is a weak acid and may be completely absorbed in small intestine due to its high solubility, high permeability and rapid dissolution properties in $\mathrm{pH} 6.8$ and biorelevant simulated intestinal fluids. On this point, using the biowaiver media in tests for BCS 2 drugs would be important to enhance the solubility and dissolution rate. As for the results of MTT tests on Caco-2 cells, there was no significant difference between the biorelevant media prepared conventionally and media prepared using the instant powder. Additionally, no meaningful difference was observed between the biorelevant media and their blanks in the Caco-2 cell viability. This means that, contrary to expectations, the main effect on cell viability was $\mathrm{pH}$, with regard to bile salt and lecithin effects. Although, the cell 
viability results for the media which reflect the fasted state were higher than the fed state media, all media were categorized as "slightly cytotoxic" with about $70-90 \%$ of cell viability. Therefore, all media might be used in Caco-2 permeability studies. The viability results of cells decreased in the ratio of $10-15 \%$ after 24 hours compared to the results at 1 hour. DMEM, a routinely used media, has a $\mathrm{pH}$ of 7.4 whereas the studied $\mathrm{pH}$ values for fasting and fed states were 6.5 and 5.0, respectively. This decrease in the viability results was related to the lower $\mathrm{pH}$ values. The cytotoxicity results using a model drug -flurbiprofen (BCS Class 2) - in two different concentrations were similar to the viability results of the media without any drug. This finding suggests that model drugs had no effect on cell viability.

In conclusion, biorelevant media is a solid method of approach in evaluating in vitro drug performance and development of new drug pharmaceuticals. However, the preparation of the method of the media is also vital for determining the efficiency of the tests. In that respect, dissolution media prepared from instant powder (such as SIF Powder") are more useful for low soluble drugs. We also saw a dramatic difference in dissolution and solubility results in the fed state of flurbiprofen - a Class 2 drug. Furthermore, these media can be used for safely performing permeability studies since the bile salts and lecithin did not cause any cytotoxic effect on the Caco 2 cells. However, minor changes in $\mathrm{pH}$ of these media can affect the results. Therefore, $\mathrm{pH}$ adjustment should be considered in further investigations.

Peer-review: Externally peer-reviewed.

Author Contributions: Concept - D.S.Y., Z.Ş.T.; Design - D.S.Y., Z.S..T.; Supervision - Z.S.T.; Resource - D.S.Y., Z.S.T.; Materials - D.S.Y., Z.S.T.; Data Collection and/or Processing - D.S.Y., S..Y., D., Z.S.T.; Analysis and/or Interpretation - D.S.Y., S.Y., D., Z.S..T.; Literature Search - D.S.Y., Z.S..T.; Writing D.S.Y., Z.S..T; Critical Reviews - D.S.Y., Z.Ş.T.

Conflict of Interest: The authors have no conflict of interest to declare.

Financial Disclosure: This study was supported by Gazi University Scientific Research Project, Project No: 02/2008-20, 2008.

\section{REFERENCES}

- $\quad$ Amidon G, Lennernàs H, Shah VP, Crison JR (1995). A theoretical basis for a biopharmaceutic drug classification: The correlation of in vitro drug product dissolution and in vivo bioavailability. Pharm Res 12: 413-420. [CrossRef]

- Antoine D, Pellequer Y, Tempesta C, Lorscheidt C, Kettel B, Tamaddon L, Jannin V, Demarne F, Lamprecht A, Béduneau A (2015). Biorelevant media resistant co-culture model mimicking permeability of human intestine. Int. J. Pharm. 481: 27 - 36. [CrossRef]

- $\quad$ Berridge MV, Herst PM, Tan AS (2005). Tetrazolium dyes as tools in cell biology: new insights into their cellular reduction. Biotechnol Annu Rev 11: 127-152. [CrossRef]

- $\quad$ Birch D, Diedrichsen RG, Christophersen PC, Mu H, Nielsen HM (2018). Evaluation of drug permeation under fed state conditions using mucus-covered Caco-2 cell epithelium. Eur J Pharm Sci 118 144-153. [CrossRef]
Boni JE, Brickl RS, Dressman J, Pfefferle ML (2009). Instant FaSSIF and FeSSIF - biorelevance meets practicality. Diss Tech 16: 41-45. [CrossRef]

- Dahl JE, Frangou-Polyzois MJ, Polyzois GL (2006). In vitro biocompatibility of denture relining materials. Gerodontology 23: 17-22. [CrossRef]

- Dressman JB, Amidon GL, Reppas C, Shah VP (1998). Dissolution testing as a prognostic tool for oral drug absorption: Immediate release dosage forms. Pharm Res 15: 11-22. [CrossRef]

- $\quad$ Fagerberg JH, Tsinman O, Sun N, Tsinman K, Avdeef A, Bergström CAS (2010). Dissolution rate and apparent solubility of poorly soluble drugs in biorelevant dissolution media. Mol Pharm 7: 1419-1430. [CrossRef]

Fatouros DG, Walrand I, Bergenstahl B, Müllertz A (2009). Colloidal structures in media simulating intestinal fed state conditions with and without lipolysis products. Pharm Res 26: 361374. [CrossRef]

Fuchs A, Leigh M, Kloefer B, Dressman JB (2015). Advances in the design of fasted state simulating intestinal fluids: FaSSIF-V3. Eur J Pharm Biopharm 94: 229-240. [CrossRef]

- Galia E, Nicolaides E, Hörter D, Löbenberg R, Reppas C, Dressman JB (1998). Evaluation of various dissolution media for predicting in vivo performance of class I and II drugs. Pharm Res 15 698-705. [CrossRef]

- Ingels F, Deferme S, Destexhe E, Oth M, Mooter G, Augustijns $p$ (2002). Simulated intestinal fluid as transport medium in the Caco-2 cell-culture model. Int J Pharm 232: 183-192. [CrossRef]

- Ingels FM, Augustijns PF (2003). Biological, pharmaceutical and analytical consideration with respect to the transport media used in the absorption screening system Caco-2. J Pharm Sci 92: 15451558. [CrossRef]

- Jantraid E, Janssen N, Reppas C, Dressman JB (2008). Dissolution media simulating conditions in the proximal human gastrointestinal tract: an update. Pharm Res 25: 1663-1676. [CrossRef]

- Kleberg K, Jacobsen F, Fatouros DG, Müllertz A (2010). Biorelevant media simulating fed state intestinal fluids: Colloid phase characterization and impact on solubilization capacity. J Pharm Sci 99 3522-3532 [CrossRef]

Klein S (2010). The use of biorelevant dissolution media to forecast the in vivo performance of a drug. AAPS J 12: 397406. [CrossRef]

- Kostewicz ES, Brauns U, Becker R, Dressman JB (2002). Forecasting the oral absorption behavior of poorly soluble weak bases using solubility and dissoxlution studies in biorelevant media. Pharm Res 19: 345-349. [CrossRef]

- Laitinen L, Takala E, Vuorela H, Vuorela P, Kaukonen AM, Marvola M (2007). Anthranoid laxatives influence the absorption of poorly permeable drugs in human intestinal cell culture model (Caco-2). Eur J Pharm Biopharm 66: 135-145. [CrossRef]

Li P, Zhao L (2003). Solubilization of flurbiprofen in pH-surfactant solutions. J Pharm Sci 92: 951-956. [CrossRef]

- Marques M (2004). Dissolution media simulating fasted and fed states. Diss Tech 11: 16. [CrossRef]

Mathias N, Xu Y, Vig B, Kestur U, Saari A, Crison J, Desai D, Vanarase A, Hussain M (2015). Food effect in humans: predicting the risk through in vitro dissolution and in vivo pharmacokinetic models. AAPS J 17: 988-998. [CrossRef]

Nicolaides E, Galia E, Efthymiopoulus C, Dressman JB, Reppas C (1999). Forecasting the in vivo performance of four low solubility drugs from their in vitro dissolution data. Pharm Res 12: 18761882. [CrossRef]

Oh DM, Curl RL, Amidon GL (1993). Estimating the fraction dose absorbed from suspensions of poorly soluble compounds in humans: a mathematical model. Pharm Res 10: 264-270. [CrossRef] 
Istanbul J Pharm 48 (3): 82-88

- Pargal A, Kelkar MG, Nayak PJ (1996). The effect of food on the bioavailability of ibuprofen and flurbiprofen from sustained release formulations. Biopharm Drug Disp 17: 511-519 [CrossRef]

- Patel N, Forbes B, Eskola S, Murray J (2006). Use of Simulated Intestinal Fluids with Caco-2 Cells and Rat lleum. Drug Dev Ind Pharm 32: 151-161. [CrossRef]

- Tang L, Khan SU, Muhammad NA (2001). Evaluation and selection of bio-relevant dissolution media for a poorly water-soluble new chemical entity. Pharm Dev Techno/ 6: 531-540. [CrossRef]

- Wiedman TS, Liang W, Kamel L (2002). Solubilization of drugs by physiological mixtures of bile salts. Pharm Res 19: 1203-1208. [CrossRef]
- $\quad$ Xu H, Vela S, Shi Y, Marrroum P, Gao P (2017). In vitro characterization of ritonavir drug products and correlation to human in vivo performance. Mol Pharm 14: 3801-3814. [CrossRef]

- Yazdanian M, Briggs K, Jankovsky C, Hawi A (2004). The high solubility definition of the current FDA guidance on biopharmaceutical classification system may be too strict for acidic drugs. Pharm Res 21: 293-299. [CrossRef]

- Zhou Z, Dunn C, Khadra I, Wilson CG, Halbert GW (2017). Statistical investigation of simulated fed intestinal media composition on the equilibrum solubility of oral drugs. Eur J Pharm Sci 99: 95104. [CrossRef] 